\title{
Techniques of donation: 'three parents', anonymity and disclosure
}

\author{
Dr Rebecca Dimond* \\ Cardiff University School of Social Sciences
}

\begin{abstract}
The clinical application of novel in-vitro fertilisation techniques involving mitochondrial donation was legalised in the UK in 2015. Mitochondria contain genetic material and it is possibly not surprising that headlines have described the resulting baby as having 'three parents' - the intending mother and father, and the egg donor. The techniques raise important questions, including how do we interpret transfer of biological material from one body to another? What are the implications for identity? And how, whether or when should the use of these techniques be revealed to the child? This article has two aims. First, it sets out the key ethical issues raised by the clinical introduction of mitochondrial donation. Secondly, it presents empirical data to highlight how patients themselves respond to these ethical questions. It concludes by highlighting how the introduction of medical technologies and the relationships between donors and recipients are dependent on the cultural, historical and social contexts.
\end{abstract}

\section{Introduction}

In March 2015, UK Parliament voted to change the law to support the clinical application of novel in-vitro fertilisation (IVF) procedures which involve the transfer of nuclear material into an enucleated donated egg. These techniques are widely known as mitochondrial donation. The result is that the UK is at the cutting edge of mitochondrial science and the only country in the world to legalise germ-line technologies. Scientific, medical and patient communities across the world have closely followed the developments with interest. In September 2015, the Human Fertilisation and Embryology Authority (HFEA) announced their plans for how centres will be licensed and what expectations will be placed on those centres to engage in monitoring babies born using the technique. It is expected that the first cohort of 'three parent' babies will be born in the UK in 2016, and as was the case following the birth of the first IVF baby, Louise Brown, in 1978 and again when she gave birth to her first child at the age of 28 , it might be expected that the health and development of these children, and potentially their future children will be watched with interest.

* DOI $10.7590 / 221354015 \mathrm{X}_{14488} 86_{72} 6_{22} 831$ 
The techniques have attracted intense scientific, media and public interest, with spectres of 'three parent babies', 'slippery slopes' and Frankenstein science competing for headline space alongside stories of women who have experienced the pain of losing a child to mitochondrial disease. Behind the alarming headlines, techniques of mitochondrial donation raise important questions for society. These include how we should understand the transfer of genetic material from one body to another, how this might impact on the child's identity and how, whether or when children should be told about this intervention. This article aims to do two things. First, it aims to set out the key ethical issues raised by the development and clinical introduction of mitochondrial donation. Secondly, based on research exploring the patient experience of mitochondrial disease, it presents empirical data to highlight how patients themselves respond to these ethical questions. Although much has been speculated about the widespread support of these techniques by patients and patient groups, and the importance of listening to those views, this is the first article to present the views of patients in the context of recent legislation. The techniques and the political process have raised many complex issues. This article focuses on three issues: 'three parent babies', anonymity and disclosure. These topics not only illuminate some of the key aspects of the mitochondria debate but also have resonance for exploring the social and ethical aspects of many other techniques involving donation.

\section{Research Methods}

This article draws on the analysis of 21 semi-structured interviews conducted with patients diagnosed with maternally inherited mitochondrial disease. The aim of this project was twofold: to explore the patient experience of mitochondrial disease and to understand patients' perspectives on mitochondrial donation. Ethical approval was gained through the North Scotland Research Ethics Committee and participants were contacted through a national mitochondria research clinic. All names have been changed to ensure anonymity. The interviews lasted between one and two hours, and a loosely structured interview schedule was followed. The topics discussed included the experience of diagnosis, health management, communication strategies within the family and the role of reproductive technologies. Based on the author's previous experience of interviewing patients with mitochondrial disease and the difficulties of talking about controversial technologies, small cards were produced with statements printed on them, which were then used to prompt discussion. These 
cards were initially prepared as part of Q methodology, ${ }^{1}$ an established method within psychology which has now been developed to explore public understanding of science, health behaviours and technologies. ${ }^{2}$ This article also draws on publicly accessible reports prepared by the Department of Health, HFEA and Nuffield Council on Bioethics.

\section{What is mitochondria and mitochondrial disease?}

Mitochondria are small structures in the cytoplasm of a cell. The 37 genes contained in mitochondrial DNA are primarily responsible for producing the cell's energy, and make up less than $0.1 \%$ of our body's total DNA. Mitochondrial disease is caused when the mitochondria fail to function, the results of which can be extremely variable in terms of symptoms and severity. Symptoms can include diabetes, deafness, epilepsy, digestive disorders and extreme fatigue, and for many patients, the disease is progressive. The term 'mitochondrial disease' encompasses a range of disorders, including mitochondrial encephalomyopathy, lactic acidosis and stroke-like episodes (MELAS) Leber's hereditary optic neuropathy (LHON) and Leigh syndrome.

As mitochondria are derived through the oocyte, disease caused by mutations of mitochondrial DNA are only inherited through the female line. This means that while both sexes can inherit the disease it is only women who are at risk of transmitting the disease to their children. There is no cure for mitochondrial disease and the treatment options, which for most people will be strong vitamins, has limited results. In this context, the development of techniques which can prevent a child from inheriting the disease have been widely welcomed. Scientists at the Wellcome Trust Centre for Mitochondrial Research in Newcastle have developed two related techniques which involve the 'donation' of healthy mitochondria within an IVF cycle. Maternal spindle transfer involves removing the nucleus of the egg and placing it into a donated, enucleated egg. Pro-nuclear transfer involves a similar process but occurs after fertilisation. Both techniques are reported to offer women with mitochondrial disease the only opportunity for having healthy, genetically related children.

As the donor's mitochondria could be inherited by future generations, the techniques are germ-line, and a change in UK law was required for them to be offered to patients. The transition from laboratory to clinic has involved intense

$1 \quad$ S. Watts \& P. Stenner, Doing Q Methodological Research: Theory, Method and Interpretation (London: Sage 2012).

$2 \quad$ H. Farrimond \& S.E. Kelly, 'Public viewpoints on novel non-invasive technologies for prenatal genetic diagnosis', Public Understanding of Science, 22:6 (2013), 736-750. 
and extensive enquiry and debate, reflecting its controversial nature, and national and international significance. The process involved three scientific reviews by an expert panel, ${ }^{3}$ a dialogue exercise to assess public attitudes ${ }^{4}$, a call for evidence on the ethical issues organised by the Nuffield Council on Bioethics ${ }^{5}$, a public consultation $^{6}$ and government guidance on draft regulations led by the UK Department of Health, ${ }^{7}$ and several debates at the House of Commons ${ }^{8}$ and House of Lords. ${ }^{9}$

\section{'Three parent babies'}

As mitochondria contain genetic material, it is not surprising that ideas about what this might mean for genetic identity and parentage have captured the imagination, been used in alarmist headlines, and come under scrutiny. 'Three parent babies' headlines have primarily dominated the debate, ${ }^{10}$ alongside more subtle ideas of 'three person IVF', 'three person babies' and 'three person DNA'. Based on the extent of the genetic contribution and the function of the genes involved, the Department of Health does not accept that a child born through mitochondrial donation would have three parents:

3 HFEA, Third scientific review of the safety and efficacy of methods to avoid mitochondrial disease through assisted conception: update 2014, www.hfea.gov.uk/8807.html (last accessed 22/9/2015).

4 HFEA, Mitochondria replacement consultation: Advice to Government. March 2013, www.hfea.gov. uk/docs/HFEA_Authority_meeting_March_2013_-_Mitchondria_report.pdf (last accessed 22/9/2015).

5 Nuffield Council on Bioethics, Novel techniques for the prevention of mitochondrial DNA disorders: an ethical Review (London: Nuffield Council on Bioethics, 2012), www.nuffieldbioethics.org/ mitochondrial-dna-disorders (last accessed 22/9/2015).

6 Department of Health, Mitochondrial Donation: A consultation on draft regulations to permit the use of new treatment techniques to prevent the transmission of a serious mitochondrial disease from mother to child (2014), https://www.gov.uk/government/uploads/system/uploads/attachment_ data/file/285251/mitochondrial_donation_consultation_document_24_02_14_Accessible_Vo.4.pdf (last accessed 22/9/2015).

7 Department of Health, Mitochondrial Donation: Government response to the consultation on draft regulations to permit the use of new treatment techniques to prevent the transmission of a serious mitochondrial disease from mother to child (2014), https://www.gov.uk/government/uploads/ system/uploads/attachment_data/file/332881/Consultation_response.pdf (last accessed 22/9/ 2015).

8 Houses of Commons debate 3 February 2015, www.publications.parliament.uk/pa/cm201415/ cmhansrd/cm150203/debtext/150203-0002.htm (last accessed 22/9/2015).

9 House of Lords debate 24 February 2015, www.publications.parliament.uk/pa/ld201415/ ldhansrd/text/150224-0002.htm (last accessed 22/9/2015).

10 'Britain is first to legalise three-parent IVF', The Times (25 February 2015), www.thetimes. co.uk/tto/science/article4364732.ece (last accessed 22/9/2015).

$11 \quad$ Sulston et al., 'Three-person IVF', The Times (letter, 28 January 2015), www.thetimes.co. $\mathrm{uk} / \mathrm{tto} /$ opinion/letters/article4337474.ece (last accessed 22/9/2015). 
'Genetically, the child will, indeed, have DNA from three individuals but all available scientific evidence indicates that the genes contributing to personal characteristics and traits come solely from the nuclear DNA, which will only come from the proposed child's mother and father. The donated mitochondrial DNA will not affect those characteristics. ${ }^{12}$

Many of the participants interviewed for this project were aware of the complexity of the debate and its competing ideas, including the biological significance of genetic material and the role of genetics in influencing our identity. Many highlighted the small contribution of mitochondrial genes that might render it insignificant in transfer, and that overall, the metaphor of 'three parent babies' was not useful:

'[People oppose the techniques] thought there'd be three parents involved and it would pose problems with visiting rights and things, which it wouldn't be anything like that. And I did get annoyed and, and like some of the government parliament people were standing up and arguing their point against it. I thought, well if they had a daughter that was suffering and having problems you wouldn't be so [opposed] [...] they're taking a gene from another lady but as regards to her being a parent, no. It's just like, giving your heart or your lung to somebody isn't it? You don't own them.' [Participant 19]

'The dodgy gene is extracted from the mother who wants a child, isn't it, her egg? And the healthy gene is put into her egg. So the gene is a just a tiny, tiny part of it. An egg is part of you, part of your - Well, it's you. Your hair colouring, your personality, everything. [The donor] has contributed and they've supported and helped somebody, but no, I don't think it's a three-parent [...] But just to take a gene, a healthy gene and take away the bad gene, you're doing it for health reasons. You're not creating somebody else's child. Do you know what I mean? I don't think they can put a claim to it.' [Participant 24]

In some cases, the words of the participants concur with the Department of Health's advice as described previously. Following this advice, the UK government has set an important precedent: the relationship between child and donor has been characterised as one where there is no parental obligation on behalf of the donor. ${ }^{13}$ This means that while donors will be able to find out

12 Department of Health, Mitochondrial Donation: Government response to the consultation on draft regulations to permit the use of new treatment techniques to prevent the transmission of a serious mitochondrial disease from mother to child (2014) 15, https://www.gov.uk/government/uploads/ system/uploads/attachment_data/file/332881/Consultation_response.pdf (last accessed 22/9/ 2015).

13 The Human Fertilisation and Embryology (Mitochondrial Donation) Regulations 2015

(SI 2015/572), www.legislation.gov.uk/uksi/2015/572/contents/made?page=5 (last accessed $22 / 9 / 2015)$. 
whether a child has been born using their donation, children will only be able to access non-identifying information about the donor.

\section{Donor Anonymity}

The system of anonymity that will be introduced alongside mitochondrial donation techniques will have important implications for the child and their family. Many of the participants held the view that the donor should remain anonymous:

'They [the mitochondria donors] have decided that they will donate to help you have a healthy child, so therefore to me, that's where the ethics stop. They don't have any rights to sort of have contact with the child. They've decided they want to be a donor, hopefully for the right reasons, not that they then want to have claims on the child that you're having.' [Participant 3]

'It's like when you give blood; you don't know where it's going, but it's probably saving somebody's life. But you don't get to know those people. So, at the end of the day, if you give genes or cells or whatever it is, bone marrow, anything, you know somewhere along the line you've done somebody some good, but you don't know who you've done it for. But it's just something that you feel is right.' [Participant 25]

Once again, the words of the participants echo the views of the Department of Health and UK government. However, included in the legislation is provision that might open up the opportunity for children and their unknown donors to make contact. Along with their health records, the donor can provide nonidentifying information about themselves for the child if they wish, and the clinic can support a voluntary system of contact between the donor and child.

\section{Disclosure}

One key recommendation from the Department of Health, and one that relates to the uncertainty about the safety of the techniques, was that the health of any child born through mitochondrial donation should be monitored. Engaging children in follow up naturally raises ethical concerns about the genetic testing of children, ${ }^{14}$ and their potential to be medicalised

14 A.L. Bredenoord \& P. Braude, 'Ethics of mitochondrial gene replacement: from bench to bedside’, British Medical Journal (2010) 341. 
from a very early age. It is also possible, provided that there is funding in place and the participants are willing, that this follow up will extend to future generations. However, one of the key assumptions on which 'follow up' is based is that families will agree to sustained contact with the clinic. However, another fundamental issue, which might be influential in whether or not families engage in medical services, hinges on disclosure. The participants in this study had differing views about whether the child should be told:

'But I think in a way it would be cruel for the children to be told. Because it confuses things when there's no need for confusion. Because I think the mitochondrial donation should be regarded like any other sort of medical procedure. Because it's not the same as sperm donation where clearly half of the genetic material comes from a parent. I think the percentage is so small that you shouldn't - I think things should be anonymised.' [Participant 8]

'I think they should have a right to know, but I think that it should be explained first, exactly what has been used and the mind and everything else hasn't changed. The only thing that's changed is they've got a healthier life, and that is thanks to the person that donated. But apart from thanking them for giving them a better life, they're not related, it's just like having a heart bypass. Someone's put something into you that makes you function okay.' [Participant 5]

'I think the child and the parent might want to have contact later on. Again, something you might do if you have an adopted child, the child's choice but not until a lot later until they're able to make that choice. I don't think you could say no to them, they're going to have ways of researching and looking.' [Participant 17]

One of the enduring factors about family life is that many children born through assisted reproduction and those who are adopted might not be told of the origins of their birth. ${ }^{15}$ Thus even after changes to the anonymity laws in the case of adoption or sperm donation, accessing information about genetic inheritance relies very much on open disclosure practices of families. With the only recent legalisation of the techniques, combined with very little published evidence exploring the patient experience of mitochondrial disease, ${ }^{16}$ whether families disclose this information to their child following use of mitochondrial

15 M. Richards, 'A British history of collaborative reproduction and the rise of the genetic connection', in: T. Freeman, S. Graham, F. Ebtehaj \& M. Richards (eds.), Relatedness in Assisted Reproduction (Cambridge University Press 2014).

16 R. Dimond, 'Patient and family trajectories of mitochondrial disease: diversity, uncertainty and genetic risk', Life Sciences, Society and Policy 9 (2013) 1-11. 
donation is currently an unknown. This study goes some way to contribute to knowledge about how families might manage these processes following use of the mitochondrial techniques, and why some families, despite appearing enthusiastic at first, might in fact lose contact with the 'follow up' clinic.

\section{Discussion}

One of the defining characteristics of technologies involving donation is that they have the potential to produce new social relationships. Whereas blood donation might be described as an altruistic and anonymous 'gift', ${ }^{17}$ the relationship between a recipient and an organ or tissue donor will depend on many factors including whether or not the donation is from a living donor and whether the donor and recipient are already known to each other. Reproductive technologies are different again, where the relationship between a sperm or egg donor and resultant child is often more clearly defined within a legal framework. Mitochondrial donation, which involves the transfer of genetic but not nuclear material transgresses these boundaries and has led to uncertainty about how the technologies themselves, and the potential relationship between donor and child, should be regulated. The possibility of forging a relationship between donor and recipient, and the meanings that we give to these relationships are of course highly dependent on the kinds of technologies involved and the legal, social and cultural context. The recent legislation, concluding that the mitochondrial donation should not have an obligation towards the child, is important for how families themselves might make sense of these technologies.

The accounts of the participants provide further evidence of the complexity of these decisions. In deciding the role of the mitochondria donor, or whether the child should know about the techniques, participants moved easily between recognising the importance of genetic knowledge and perceiving mitochondrial DNA to have a relatively insignificant role. Importantly, participants made a distinction between donation for reproductive purposes and donation for health or avoiding illness. This distinction also became important when assessing the potential role of the mitochondria donor. Being a donor 'for the right reasons', that is, to improve health, led to the conclusion that the person should not then be allowed to claim a relationship with the child as they might in cases of sperm donation or adoption.

Participant accounts highlight how the meanings we attribute to the techniques of mitochondrial donation, mitochondrial DNA and the mitochondria

R. Titmuss, The gift relationship: From human blood to social policy (A. Oakley \& J. Ashton eds., London: LSE 1997 [1971]). 
donor are developed within a particular context. By frequently comparing mitochondrial donation with other kinds of donation, including heart donation, kidney donation, blood donation and sperm donation, participants revealed the cultural, historical and social backdrop in which relations between donors and recipients are played out. Mitochondrial donation is made sense of because it is categorised as similar, or different, to other kinds of techniques. Mitochondrial donation will allow women with mitochondrial disease the opportunity to have healthy, genetically related children. It is part of a rapidly developing field of mitochondrial medicine, involving the development of diagnostic technologies, risk assessment tools and IVF technologies. However, the techniques have challenged legal and ethical frameworks, and the translation from laboratory to clinical practice has involved a long period of scrutiny. The techniques have attracted intense media interest, and strong views have been expressed by national and international patient and scientific groups. This article has highlighted the views of patients with mitochondrial disease, and this is an important contribution. Although attitudes often differ about the central importance of mitochondrial DNA, this article has shown that patient perspectives, and the debate itself, cannot be reduced to genetic essentialist reasoning. One aspect that appeared prominent in discussions with patients was the perceived motivations of donors and parents. The focus on health rather than reproduction is possibly one of the reasons why the techniques have attracted widespread support. Indeed, although the techniques might have wider benefit than those with mitochondrial disease, other potential uses have been ruled out, including for fertility purposes $^{18}$ and for lesbian couples who wish to use the techniques so that both parties can provide a genetic contribution. Of course questions remain about what will happen in practice, and many countries across the world will be watching and waiting with interest as to how children, parents, families, donors and UK institutions negotiate these contentious issues.

18 C. Smyth, 'Allow three-parent IVF to help older women too, says pioneer', The Times (9 February 2015), www.thetimes.co.uk/tto/health/news/article4348194.ece (last accessed 22/9/2015). 